\title{
Assessment of activated sludge, membrane bioreactors and vertical flow wetlands for upgrading sewage treatment works
}

\author{
A Besancon $^{1}$, K S Le Corre ${ }^{2}$, G Dotro $^{2 *}$, B Jefferson ${ }^{2}$ \\ ${ }^{1}$ Evac E.U.R.L., 35/37 avenue du gros Chêne, B.P. 50098, 95613 Cergy-Pontoise Cedex, \\ France \\ ${ }^{2}$ Cranfield University, Cranfield, Bedfordshire, MK43 0AL, UK
}

\begin{abstract}
This paper demonstrates that utilising a vertical flow (VF) wetland after a conventional activated sludge (CAS) delivers equivalent or better effluent quality to a membrane bioreactor (MBR) based on a side-by-side pilot trial. A CAS, an MBR and a CAS+VF system were run in parallel for 18 months under controlled conditions. The CAS was operated under the solids retention times (SRT) of 6, 12, and 20 days, with the effluent from each pilot plant fed onto a soil aquifer treatment column to better understand their water reuse application potential. Results showed an upgraded CAS+VF system could deliver effluents with median values of $34 \mathrm{mgO}_{2} \cdot \mathrm{L}^{-1}, 7 \mathrm{mg} . \mathrm{L}^{-1}$ and $1.9 \mathrm{mg} . \mathrm{L}^{-1}$ for organics, solids and ammonia nitrogen, respectively, which were statistically similar to those from the MBR. Water reuse standards were achieved by the upgraded system for most parameters, with the exception of total coliform removal. The upgraded system delivered superior metal removal when compared to the CAS, regardless of the operating SRT. An economic analysis showed upgrading a CAS with a VF wetland was more favourable than investing in an MBR system for example works of 5,000 and 50,000 population equivalents if the VF system was operated at hydraulic loading rates of $0.03 \mathrm{~m} . \mathrm{d}^{-1}$ and $0.08 \mathrm{~m} . \mathrm{d}^{-1}$, respectively. This was delivered for a tenth of the carbon footprint of the MBR treatment. The equivalent water reuse quantities potentially treated by the CAS+VF system translated into $0.38 \mathrm{Mm}^{3}$.year ${ }^{-1}$ and $3.8 \mathrm{Mm}^{3}$.year ${ }^{-1}$, respectively, highlighting the relevance of VF wetlands for sewage upgrade in reuse applications.
\end{abstract}

\section{Keywords}

water reuse; solids; nitrification; metals; aquifer recharge

\section{Introduction}

The pressure on water resources has consistently increased worldwide, with a resulting need for alternative management strategies including water reuse. For example, current reuse levels of treated wastewater in Singapore, Saudi Arabia, and Israel are estimated to account for around $30 \%, 16 \%$, and $70 \%$ of their total wastewater production [1]. Indeed, whilst the US only reuses $8 \%$ of its total wastewater production, the US Environment Protection Agency published their revised Water Reuse Guidelines in late 2012 with the view of increasing the number of reuse schemes in that country [1]. Worldwide, a review of water reuse and reclamation has identified that there are over 3,300 such 
schemes for various applications, the main ones being for agricultural and industrial uses [2]. These required water qualities ranging from secondary treated effluents to quaternary treatment. One strategy for water reuse that is gaining interest is to artificially recharge aquifers, either by direct injection onto the water table (i.e., deep well injection; [3]) or by passing the treated water through soil aquifer treatments (SATs) to feed the groundwater [4, 5]. The efficacy of SATs in terms of both the hydraulic productivity and the final produced quality entering the aquifer depends on the effluent quality coming from sewage treatment works. Accordingly current practice is to enhance the quality of the treated effluents by extending the solids retention time of the conventional activated sludge plant (CAS; [6]), coupled to downstream multi-media filters [5] or membranes [7] commonly implemented by replacing the CAS with a membrane bioreactor (MBR; [8]). The latter has been widely recognised to produce reliable effluent qualities that meet most standards at lower footprint than CAS [9]. However, the relatively high capital and operational costs associated with the use of membranes limit their implementation at large scale and would constitute a significant barrier for implementation in developing countries [10]. Consequently, alternative upgrade technologies need to be considered that provide full or partial equivalence to the treatment delivered through the use of membranes whilst greatly reducing costs, energy, complexity and maintenance. The proposed challenge extends beyond just water reuse and relates perhaps most pertinently to general sewage effluent upgrade, especially in treatment plants serving small populations. Such sites are increasingly being required to meet more restrictive discharge consents in relations to organics, solids and ammonia and so need upgrading to ensure continued compliance as the discharge consents change.

The current paper considers the use of vertical flow (VF) wetlands to meet such needs as they provide enhanced multiple treatment pathways through a combination of filtration and aerobic biofilms. These systems were developed as a treatment technology in the early 60 s and since then have been employed mainly for primary [11] and secondary [12] treatment of municipal wastewaters. Consequently, examples of them being used as tertiary treatment systems to upgrade more energy intensive systems such as activated sludge are extremely limited [13-15]. Indeed, whilst wetlands have been proposed as treatment technology in a reuse application, these are mainly limited to onsite systems (e.g., flushing toilets), small residential developments or to replenish natural wetlands [16]. However, none of these have been compared against the more established preference for membranes complicating the technology assessment and selection procedure for water reuse and general effluent upgrading.

This paper attempts to populate this space by presenting results from a side by side assessment of extensive (i.e., VF wetlands) and intensive (i.e., MBRs) treatment technologies as an upgrading approach for CAS for municipal wastewater treatment. Treated effluent quality is benchmarked against a stand-alone CAS unit operated at different solids retention times (SRTs) to ascertain if extended SRTs are necessary when appropriate upgrade technologies are included. The comparison is used to discuss the trade off between land footprint and energy afforded by the two technologies within the context of aquifer recharge and sewage effluent upgrading.

\section{Materials and Methods}

Pilot plant systems

Settled sewage obtained from the treatment plant at Cranfield University was fed to three pilot-scale 
treatments: a $35 \mathrm{~L}$ membrane bioreactor with a surface area of $0.2 \mathrm{~m}^{2}$, a conventional activated sludge system composed of a $30 \mathrm{~L}$ aeration tank and a $7 \mathrm{~L}$ clarifier; and $1 \mathrm{~m}$ deep, $0.2 \mathrm{~m}^{2}$ vertical flow wetlands following primary settlement and CAS (Figure 1). The CAS and MBR were operated at 6,12 , and 20 days SRT and 8 hour hydraulic retention time. Volumetric throughput was $105 \mathrm{~L} \cdot \mathrm{d}^{-1}$ and $91{\mathrm{~L} . \mathrm{d}^{-1}}^{-1}$ for the MBR and the CAS, respectively. The wetlands were designed and operated based on [17], filled with $0.15 \mathrm{~m}$ of filter grade sand $(0.5-1 \mathrm{~mm}), 0.15 \mathrm{~m}$ of pea gravel $(10 \mathrm{~mm})$, $0.05 \mathrm{~m}$ of gravel $(20 \mathrm{~mm})$ and $0.6 \mathrm{~m}$ of gravel $(40-50 \mathrm{~mm})$ from the top to the bottom. All beds were planted with Phragmites australis and contained a passive aeration pipe. The wetlands were operated under conservative hydraulic loadings of 0.01 and $0.05 \mathrm{~m} . \mathrm{d}^{-1}$ for the CAS+VF and VF respectively in order to establish the potential to mirror the treatment efficacy of the MBR. The beds were fed intermittently 8 times per day, each time for 10 minutes. All treatments were followed by a pilotscale soil column, representing the receiving SAT. The SAT columns were operated under unsaturated conditions, at a constant head of $5 \mathrm{~cm}$ and a rotation of 7 days wetting and 7 days resting (drying periods). Columns were made of clear PVC pipes with an internal diameter of $2.6 \mathrm{~cm}$ and 1.3 $\mathrm{m}$ length. The SATs were filled with $10 \mathrm{~cm}$ of gravel and $1 \mathrm{~m}$ of sieved $(2 \mathrm{~mm}$ mesh) and repacked with material from the Shafdan soil aquifer treatment site (Israel) at $1.5 \mathrm{~g}_{\mathrm{cm}} \mathrm{cm}^{-3}$ density. The Shafdan aquifer is unconfined and mainly consists of sand and sandstone [18]. Details on the geology of the aquifer and it characteristics can be found in [19]

\section{[Insert Figure 1 here]}

\section{Sampling and analysis}

Grab samples were collected weekly for 18 months at the inlet and outlet of each unit process to assess their performance. Analysis was conducted for chemical oxygen demand (COD), ammonia $\left(\mathrm{NH}_{4}-\mathrm{N}\right)$ and nitrate nitrogen $\left(\mathrm{NO}_{3}-\mathrm{N}\right)$ using test kits (Spectroquant Cell Test, Merck, Poole, UK) and a spectrophotometer (Nova 60, Merck, Poole, UK). Total coliforms, total suspended solids (TSS) and $\mathrm{pH}$ were determined according to Standard Methods [20]. Samples for metal analysis were filtered before concentrated nitric acid was added to a level of $5 \%$ volume of the matrix prior to analysis using inductively coupled plasma mass spectroscopy (Perkin Elmer SCIEX ELAN 9000 ICP-MS and CETAC ASX-510 auto sampler). Effluent data was tested for normality and analysed with a Kruskal-Wallis test at the 0.05 level of significance. All statistical testing was performed with STATISTICA v11 (StatSoft, Bedford, UK).

The infiltration rate of the soil columns was calculated dividing the volume of wastewater that passed through the soil in one day by the cross sectional area of the columns. This was assessed daily to quantify the impact of the different treatments on the receiving SATs. Infiltration was adjusted taking into account the water temperature using the Arrhenius equation. Weekly averages were used to compare infiltration rates against accumulated solids.

\section{Financial and carbon assessment}

The CAS and both upgrade options (i.e., MBR and VF) were further assessed in terms of their capital, operation and maintenance costs; land requirements; and operational carbon footprint. All calculations were based on 1 population equivalent (p.e.) producing $60 \mathrm{~g}$ organic matter (measured as 5-day biochemical oxygen demand), $7.6 \mathrm{gNH}_{4}-\mathrm{N}$, and $70 \mathrm{gTSS}$. The costs were based on a 
treatment works for 5,000 p.e. and 50,000 p.e., to achieve an effluent consent of $10 \mathrm{mg} . \mathrm{L}^{-1} \mathrm{BOD}, 15$ $\mathrm{mg} . \mathrm{L}^{-1} \mathrm{TSS}$, and $3 \mathrm{mg} . \mathrm{L}^{-1}$ ammonia. Operational costs were calculated per year and a present worth analysis was conducted using a 5\% discount rate for a period of 20 years. The CAS and MBR include the requirements associated with final settling and fine screening, respectively. The price of electricity was $£ 0.092 . \mathrm{kWh}^{-1}$. The MBR and CAS costs were based on a UK water industry report [21]. The vertical flow wetlands were hydraulically sized to match the loading rates used in this study and include partial refurbishment of the bed 10 years after construction to alleviate clogging in line with current asset life estimations [22]. Wetland costs were obtained from a utility company cost curves and were based on $1.1 \mathrm{~m}$ excavations (wetland basins) fed by intermittent pumps operating with the same pattern as in the pilot plants.

\section{Results and Discussion \\ Wastewater Quality}

All treatments were able to reliably reduce pollutant loadings to below $100 \mathrm{mg} . \mathrm{L}^{-1}$ COD and $4 \mathrm{mg} . \mathrm{L}^{-}$ 1 ammonia (Figure 2) even with the high variation of the influent quality (Table 1). Results indicated enhanced treatment in the MBR and CAS $+\mathrm{VF}$ in terms of COD, total solids and total coliforms with respect to both the median values and the ranges at the three SRTs tested $(p<0.05)$. In terms of nutrients, statistical analysis indicated that only nitrates at SRTs of 6 and 12 days were significantly different. Overall this was expected as removal of total nitrogen and phosphorus were not the primary design target, consistent with typical small works requirements. Nitrification was good in all systems, as expected when operated under fixed flow conditions. The MBR was the benchmark treatment and performed as expected, producing similar effluent quality regardless of the changes in influent quality or SRT used. Overall the CAS+VF performed effectively in comparison to the MBR and even exceeded treatment in terms of COD and ammonia during the 20 day SRT. The secondary VF wetland achieved similar performance to the CAS under the test conditions, confirming that in both comparisons the trade off between footprint and energy can be effectively considered without compromising the achievable effluent quality.

\section{[Insert Figure 2 here]}

\section{[Insert Table 1 here]}

The efficacy of VF wetlands as a tertiary upgrade option has been demonstrated by comparing against MBR treatment. The efficacy of the option holds across different sludge ages enabling systems currently set up on relatively short SRTs to be upgraded without alteration to the existing assets. The systems were set up to reflect standard small works practice and so contained no specific adaptation for total nitrogen or phosphorus removal. Consequently, for systems requiring advanced nutrient removal further adaption would be required such as inclusion of recirculation [12] or intermittent aeration [23] for total nitrogen and either adsorptive media or chemical dosing for enhanced phosphorus removal [24].

Metal removal was generally enhanced at the 6 day sludge age compared to the 20 day sludge age for all systems and was in the order MBR $>\mathrm{CAS}+\mathrm{VF}>\mathrm{CAS}=\mathrm{VF}$ (Table 2). This is consistent with previous studies that have suggested that reduced metal removal is attributed to increased 
complexation and solubilisation at higher sludge ages through the production of additional soluble microbial products [25, 26]. Overall, removal in the MBR was lower than reported elsewhere [27]. This could be attributed to the larger pore size used for the membrane in the current study.

\section{[Insert Table 2 here]}

Hazardous chemicals removal was also evaluated on the pilot plants, the results of which can be found on [28]. Briefly, coupling the vertical flow wetland to the activated sludge system enhanced removal of hazardous chemicals to a level equivalent or slightly better than the MBR further demonstrating the efficacy of the alternative approach.

\section{Impact on soil aquifer treatment}

The infiltration rate of the SAT column fed with MBR permeate remained higher than the other systems across the majority of the trial commensurate with the lower total solids concentration (Figure 3). To illustrate, average infiltration rates (adjusted for temperature) $\mathbf{d}$ day SRT were 64.2, 51.9 and $18.9 \mathrm{~cm} . \mathrm{d}^{-1}$ for the MBR system and compared to 28.6. 21.9 and 6.8 $\mathrm{cm} . \mathrm{d}^{-1}$ in the case of the CAS+VF system. The similarity in the average infiltration between the 6 and 20 day SRT periods is in part explained by changes in the water temperature which averaged 7.9, 14.4 and $5.4{ }^{\circ} \mathrm{C}$ during the 6,20 and 12 day SRT test periods. Analysis across the trial revealed a statistically significant inverse relationship between the influent solids load and the permeability of the SAT for the MBR and the CAS+VF systems (Figure 3b). This is consistent with the better effluent quality obtained in these two advanced treatment processes [1]. No significant correlation was found for the CAS and the secondary VF effluents with SAT infiltration rates measured. The CAS effluent solids variability was reflected in the infiltration rates of the corresponding SAT.

\section{[Insert Figure 3 here]}

The finding that all systems resulted in clogging of the receiving SAT irrespective of the applied solids loading was unexpected and implied that solids loading is not the dominant factor in SAT clogging. Consideration is consequently given towards biological fouling which is common in filtering technologies, including MBRs [9] and wetlands [29] and has been attributed to diminished infiltration rates in deep well injection systems [3] and infiltration galleries [30]. Analysis of the performance data supports such a proposition as reduced clogging and longer SAT life was observed in the MBR and CAS+VF where reduced organic loads were exerted onto soils enabling maintenance of aerobic conditions and faster degradation processes of the retained organic matter. The increase in the normalised infiltration rates during the summer months further supports this as increased biological activity can be expected as the average temperature rose from $8^{\circ} \mathrm{C}$ to $14^{\circ} \mathrm{C}$. Overall, the results reflect the complex relationships that govern SAT permeability and indicate that reduction in organics and nutrients as well as solids are probably required for sustained operation.

\section{Implications for sewage upgrade implementation}

Inclusion of VF wetlands into existing CAS works provides an effective mean of upgrading sewage treatment whilst retaining the existing asset base. Applicability is shown towards site needing either improvement in ammonia or organics removal and/or micro-pollutants. Accordingly, operation under 
shorter sludge age is permissible, reducing aeration demand and enhancing metal removal. The use of VF wetland reduces the pressure on optimising single unit processes by adding buffering capacity as well as degradation and sorption pathways, thus enabling a more resilient approach to meeting tight discharge consents at small works. An interesting extension of the current findings relates to upgrade post fixed film processes such as trickling filters or rotating biological contactors, commonly used in smaller works. When these smaller sites are required to deliver improved effluent quality, it is common to replace the fixed film processes with activated sludge systems or upgrade them with aerated horizontal flow wetlands [31], both at significant operational costs. Thus, an upgrade with VF wetlands at smaller works is also of pertinent and timely consideration and should be a focus of future investigation.

A second and perhaps one of the most important applications of sewage effluent upgrade is for water recycling including large volume operations such as aquifer recharge or irrigation that effectively offsets potable demand. Assessment of the potential for the different option is considered through comparison to current guidelines for SAT or irrigation (Table 3). Notably, the combination of CAS+VF matched the MBR performance in all parameters except on nitrate discharges with severe restrictions, where CAS, CAS+VF and VF outperformed the MBR; and total coliforms, where MBR was the only one to produce a compliant effluent.

\section{[Insert Table 3 here]}

The choice of appropriate technology for sewage effluent upgrade across the different possible applications is ultimately a trade-off between criteria identified by stakeholders and the limitations of the technologies. In this context, the most pertinent trade off is between land footprint and cost with additional consideration of carbon footprint, maintenance and repair (Table 4). Results showed the capital cost for the upgraded CAS was significantly higher than both the CAS alone and the MBR. However, when considering the assets' whole life costs in terms of present worth, the upgrade with a VF wetland offered a more effective investment for a small works (i.e., 5,000 p.e.). In contrast, for the larger works scenario, the higher rate MBR process provided the lowest total cost option congruent with current perceptions that extensive treatment systems are better suited to small works or locations where land availability and pricing is not an issue.

\section{[Insert Table 4 here]}

The experimental work utilised a conservative hydraulic loading $\left(0.05 \mathrm{~m} \cdot \mathrm{d}^{-1}\right)$ for the tertiary VF wetland to maximise effluent quality. To further elucidate the potential of VF wetlands, the whole life costs were calculated for a range of HLRs to establish the economic parity with the MBR (Figure 4). In the case of the small works, parity required an HLR of $0.03 \mathrm{~m} . \mathrm{d}^{-1}$, verifying the overall suitability of the options. In the case of the larger scale, an increase to a hydraulic loading rate of $0.076 \mathrm{~m} . \mathrm{d}^{-1}$ was required, representing a $52 \%$ intensification in the process. Comparison with reported systems indicates HLR in other tertiary applications to be between 0.06 and $0.26{\mathrm{~m} . \mathrm{d}^{-1}}^{-13}$, 32] providing confidence that such intensification is achievable. Accordingly, VF wetlands provide an appropriate approach even at larger scales although the impact on effluent quality needs confirmation to ensure water quality parity to the lower loading systems. The significance relates to 
the applicability towards reuse where scales vary from less than $0.01 \mathrm{Mm}^{3}$ per year to over $5 \mathrm{Mm}^{3}$ per year, depending on the geographical location of treatment systems and the intended reuse application [2]. The results from this study would represent annual reuse quantities of 0.38 $\mathrm{Mm}^{3}$.year ${ }^{-1}$ and $3.8 \mathrm{Mm}^{3}$.year ${ }^{-1}$, for 5,000 and 50,000 p.e., respectively. As such, there are within the range of reuse quantities currently being exploited. Whilst the benefits to the aquifer system being recharged through an upgraded CAS as proposed in the current study are expected to be higher at larger scale (i.e., 50,000 p.e.), there is a clear possibility of smaller contributions to the aquifer within more rural areas at a reduced environmental (as carbon) and financial (as present worth) cost than the conventional MBR solution.

\section{[Insert Figure 4 here]}

\section{Conclusions}

The efficacy of VF wetlands as a means of sewage works upgrading has been demonstrated, achieving parity or exceeding the effluent quality of an MBR in terms of COD, ammonia and hazardous chemicals. Importantly, the vertical flow wetland enabled the upstream CAS process to be operated at low SRTs, reducing aeration demand and maximising metal removal. The VF option offers whole life cost parity to the MBR option at hydraulic loading rate of $0.03 \mathrm{~m} . \mathrm{d}^{-1}$ for a 5,000 p.e. plant and $0.08 \mathrm{~m} . \mathrm{d}^{-1}$ for a 50,000 p.e. plant, suggesting VF can be used as upgrade for sewage works discharging to the natural environment or in a water reuse application.

\section{Acknowledgements}

This work was supported by the European Commission within the RECLAIM WATER project under contract number 018309 in the Global Change and Ecosystem sub-priority of the $6^{\text {th }}$ Framework Programme. 


\section{References}

[1] EPA, U.S., Guidelines for water reuse, Cincinnati, OH, USA 2012.

[2] Ghermandi, A., Bixio, D., Thoeye, C., The role of free water surface constructed wetlands as polishing step in municipal wastewater reclamation and reuse. $C$ -258 .

[3] Pavelic, P., Dillon, P.J., Barry, K.E., Vanderzalm, J.L., et al., Water quality effects on clogging rates during reclaimed water ASR in a carbonate aquifer. J. Hydrol. 2007, 334, 1-16.

[4] Asano, T., Cotruvo, J.A., Groundwater recharge with reclaimed municipal wastewater: health and regulatory considerations. Water Res. 2004, 38, 1941-1951.

[5] Bekele, E., Toze, S., Patterson, B., Higginson, S., Managed aquifer recharge of treated wastewater: Water quality changes resulting from infiltration through the vadose zone. Water Res. 2011, 45, 5764-5772.

[6] Aguilera Soriano, G., Erb, M., Garel, C., Audic, J.M., A comparative pilot-scale study of the performance of conventional activated sludge and membrane bioreactors under limiting operating conditions. Water Environ. Res. 2003, 75, 225-231.

[7] Raffin, M., Germain, E., Judd, S., Optimisation of MF membrane cleaning protocol in an Indirect Potable Reuse (IPR) scheme. Sep. Purif. Technol. 2011, 80, 452-458.

[8] Kazner, C., Wintgens, T., Dillon, P., Water reclamation technologies for safe manager aquifer recharge, IWA Publishing, 2012.

[9] Judd, S.J., The MBR book: principles and applications of membrane bioreactors for water and wastewater treatment, Elsevier Science, Netherlands 2011.

[10] Bixio, D., De Heyder, B., Cikurel, H., Muston, M., et al., Municipal wastewater reclamation: Where do we stand? An overview of treatment technology and management practice. Water Sci. Technol. Water Supply 2005, 5, 77-85.

[11] Molle, P., Liénard, A., Boutin, C., Merlin, G., et al., How to treat raw sewage with constructed wetlands: An overview of the French systems. Water Sci. Technol. 2005, 51, 11-21.

[12] Brix, H., Arias, C.A., The use of vertical flow constructed wetlands for on-site treatment of domestic wastewater: New Danish guidelines. Constr. Wetl. Wastewater Treat. 2005, 25, 491500 .

[13] Schönerklee, M., Koch, F., Perfler, R., Haberl, R., et al., Tertiary treatment in a vertical flow reed bed system - A full scale pilot plant for 200-600 P.E. Proc. 1996 th Int. Conf. Wetl. Syst. Water Pollut. Control 1997, 35, 223-230.

[14] Cooper, P., The performance of vertical flow constructed wetland systems with special reference to the significance of oxygen transfer and hydraulic loading rates. Water Sci. Technol. 2005, 51, 81-90.

[15] Xie, X.-L., He, F., Xu, D., Dong, J.-K., et al., Application of large-scale integrated verticalflow constructed wetland in Beijing Olympic forest park: design, operation and performance. Water Environ. J. 2012, 26, 100-107.

[16] Rousseau, D.P.L., Lesage, E., Story, A., Vanrolleghem, P.A., et al., Constructed wetlands for water reclamation. AQUAREC 2006 Integr. Concepts Reuse Upgrad. Wastewater AQUAREC 2006 CHEMECA 2006 34th Annu. Australas. Chem. Process Eng. Conf. CHEMECA 2006 2008, 218, 181-189.

[17] Grant, N., Griggs, J., Reed beds for the treatment of domestic wastewater, CRC, Construction Research Communications Limited, 2001.

[18] Le Corre, K., Aharoni, A., Cauwenberghs, J., Chavez, A., et al., Water reclamation for aquifer recharge at the eight case study sites: a cross case analysis. 2012, 11-31.

[19] Oren, O., Gavrieli, I., Burg, A., Guttman, J., et al., Manganese Mobilization and Enrichment during Soil Aquifer Treatment (SAT) of Effluents, the Dan Region Sewage Reclamation Project (Shafdan), Israel. Environ. Sci. Technol. 2007, 41, 766-772.

[20] Washington, D.C., American Public Health Association (APHA), . Standard Methods for the 
Examination of Water and Wastewater (21st ed., 2005.

[21] UKWIR, Chemical Investigation program: Llanbedr pilot plant study., UK Water Industry Research, London, UK 2013.

[22] UKWIR, The Performance of Sustainable Wastewater Treatment Works Solutions, UK Water Industry Research, London, UK 2011.

[23] Kraume M., Bracklow, U., Vocks, M., Drews, A., Nutrients removal in MBRs for municipal wastewater treatment. Water Sci. Technol. 2005, 51, 391-402.

[24] Dotro, G., Fort, R., Barak, J., Jones, M., et al., Long-term performance of constructed wetlands with chemical dosing for phosphorus removal, in: Vymazal, J. (Ed.), The Role of Natural and Constructed Wetlands in Nutrient Cycling and Retention on the Landscape, Springer International Publishing, 2015, pp. 273-292.

[25] Sterritt, R.M., Lester, J.N., The influence of sludge age on heavy metal removal in the activated sludge process. Water Res. 1981, 15, 59-65.

[26] Stephenson, T., Lester, J.N., Heavy metal behaviour during the activated sludge process. I. Extent of soluble and insoluble metal removal. Sci. Total Environ. 1987, Vol. 63, 199-214.

[27] Fatone, F., Bolzonella, D., Battistoni, P., Cecchi, F., Removal of nutrients and micropollutants treating low loaded wastewaters in a membrane bioreactor operating the automatic alternatecycles process. Desalination 2005, 183, 395-405.

[28] Reif, R., Besancon, A., Le Corre, K., Jefferson, B., et al., Comparison of PPCPs removal on a parallel-operated MBR and AS system and evaluation of effluent post-treatment on vertical flow reed beds. Water Sci. Technol. 2011, 63, 2411-2417.

[29] Knowles, P., Dotro, G., Nivala, J., García, J., Clogging in subsurface-flow treatment wetlands: Occurrence and contributing factors. Ecol. Eng. 2011, 37, 99-112.

[30] Bekele, E., Toze, S., Patterson, B., Fegg, W., et al., Evaluating two infiltration gallery designs for managed aquifer recharge using secondary treated wastewater. J. Environ. Manage. 2013, $117,115-120$.

[31] Butterworth, E., Dotro, G., Jones, M., Richards, A., et al., Effect of artificial aeration on tertiary nitrification in a full-scale subsurface horizontal flow constructed wetland. Ecol. Eng. 2013, 54, 236-244.

[32] Torrens, A., Molle, P., Boutin, C., Salgot, M., Impact of design and operation variables on the performance of vertical-flow constructed wetlands and intermittent sand filters treating pond effluent. Water Res. 2009, 43, 1851-1858. 
Table 1. Influent wastewater characteristics

\begin{tabular}{lccccccccc}
\hline Parameter & \multicolumn{3}{c}{ Influent $(6)^{*}$} & \multicolumn{3}{c}{ Influent(12)* } & \multicolumn{3}{c}{ Influent(20)* } \\
& Median & Max & Min & Median & Max & Min & Median & Max & Min \\
\hline $\begin{array}{l}\text { COD } \\
\left(\mathrm{mg} . \mathrm{L}^{-1}\right)\end{array}$ & 249 & 314 & 130 & 307 & 630 & 126 & 399 & 728 & 194 \\
$\begin{array}{l}\text { TSS } \\
\left(\mathrm{mg} . \mathrm{L}^{-1}\right)\end{array}$ & 87 & 106 & 41 & 105 & 386 & 30 & 120 & 592 & 40 \\
$\begin{array}{l}\mathrm{NH}-\mathrm{N} \\
\left(\mathrm{mg} . \mathrm{L}^{-1}\right)\end{array}$ & 27 & 43 & 17 & 29 & 37 & 11 & 29 & 42 & 16 \\
$\begin{array}{l}\text { TP } \\
\left(\mathrm{mg} . \mathrm{L}^{-1}\right)\end{array}$ & 6 & 8 & 3 & 7 & 15 & 5 & 12 & 25 & 3 \\
$\begin{array}{l}\text { Total coliforms } \\
\left(\mathrm{cfu} .100 \mathrm{~mL}^{-1}\right)\end{array}$ & 225,000 & 752,000 & 1,760 & 152,000 & 270,000 & 8,000 & 160,000 & 420,000 & 4,000 \\
\hline
\end{tabular}

$382 *$ Numbers in brackets refer to the 6 months of operation at each SRT used in the conventional activated 383 sludge plant component of the treatment flowsheet. 
385 Table 2 Summary of metal performance at extreme SRTs

386

\begin{tabular}{cccccccc}
\multirow{2}{*}{$\begin{array}{c}\text { SRT } \\
(\text { days })^{*}\end{array}$} & Wastewater & \multicolumn{3}{c}{ Concentration $\left(\mu \mathrm{g} . \mathrm{L}^{-1}\right)$} & \multicolumn{3}{c}{ Removal $(\%)$} \\
\cline { 2 - 7 } & & $\mathrm{Zn}$ & $\mathrm{Cu}$ & $\mathrm{Mn}$ & $\mathrm{Zn}$ & $\mathrm{Cu}$ & $\mathrm{Mn}$ \\
\hline 6 & Influent & 180 & 25 & 113 & $n / a$ & $n / a$ & $n / a$ \\
& MBR & 109 & 2.5 & 39.2 & 40 & 90 & 65 \\
& $\mathrm{CAS}+\mathrm{VF}$ & 159 & 22.4 & 26.4 & 12 & 10.4 & 77 \\
& $\mathrm{CAS}$ & 132 & 9.6 & 47 & 27 & 61.6 & 58 \\
\hline 20 & Influent & 380 & 20 & 65 & $n / a$ & $n / a$ & $n / a$ \\
& MBR & 314 & 3.3 & 31.8 & 17 & 84 & 51 \\
& CAS+VF & 382 & 4.8 & 25.8 & 0 & 76 & 60 \\
& $\mathrm{CAS}$ & 332 & 6 & 45.2 & 13 & 70 & 30
\end{tabular}
plant component of the treatment flowsheet. 
Table 3 Reuse targets compliance for upgrade options and CAS. Reuse standards are for SAT, irrigation with severe restrictions (ISR), irrigation with moderate restrictions (IMR) and irrigation unrestricted (IU; Bixio and Wintgens, 2006; WHO, 2006; Kretschmer, Ribbe and Gaese, 2002; Asano and Levine, 1998).

\begin{tabular}{|c|c|c|c|c|c|c|c|c|c|c|c|}
\hline \multirow[b]{2}{*}{ Parameter } & \multicolumn{5}{|c|}{ MBR } & \multicolumn{3}{|c|}{ CAS } & \multicolumn{3}{|c|}{ CAS + VF } \\
\hline & $\begin{array}{l}\text { Reuse } \\
\text { Application }\end{array}$ & Limit & $6 d$ & $12 d$ & $20 d$ & $6 d$ & $12 d$ & $20 d$ & $6 d$ & $12 d$ & $20 d$ \\
\hline \multirow{4}{*}{$\begin{array}{c}\mathrm{COD} \\
\left(\mathrm{mgO}_{2} \cdot \mathrm{L}^{-1}\right)\end{array}$} & SAT & $70-100$ & $\checkmark$ & $\checkmark$ & $\checkmark$ & $\checkmark$ & $\checkmark$ & $x$ & $\checkmark$ & $\checkmark$ & $\checkmark$ \\
\hline & ISR & $<100$ & $\checkmark$ & $\mathscr{L}$ & $\checkmark$ & $\checkmark$ & 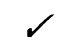 & 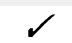 & r & $\Omega$ & 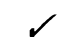 \\
\hline & IMR & & & & & & & & & & \\
\hline & IU & $<50$ & $\checkmark$ & 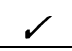 & $\checkmark$ & $x$ & $x$ & $\checkmark$ & $\mathscr{L}$ & $\mathscr{L}$ & 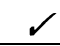 \\
\hline \multirow{4}{*}{$\begin{array}{c}\text { TSS } \\
\left(\mathrm{mg} \cdot \mathrm{L}^{-1}\right)\end{array}$} & SAT & $<10$ & $\Omega$ & $\Omega$ & $\checkmark$ & $x$ & $x$ & $x$ & $r$ & $\Omega$ & $\Omega$ \\
\hline & ISR & $<100$ & $\checkmark$ & 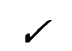 & $\checkmark$ & $\checkmark$ & $\mathscr{r}$ & $\checkmark$ & $\mathscr{r}$ & $\Omega$ & $\mathscr{l}$ \\
\hline & IMR & $50-100$ & $\checkmark$ & 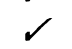 & $\checkmark$ & $\checkmark$ & $\checkmark$ & $\checkmark$ & r & $\alpha$ & $\mathscr{l}$ \\
\hline & $\mathrm{IU}$ & $<50$ & $\Omega$ & $\Omega$ & $\checkmark$ & $\Omega$ & $\Omega$ & $\checkmark$ & 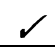 & 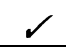 & $\mathscr{L}$ \\
\hline \multirow{4}{*}{$\begin{array}{l}\mathrm{NH}_{4}-\mathrm{N} \\
\left(\mathrm{mg} \cdot \mathrm{L}^{-1}\right)\end{array}$} & SAT & $<2$ & $\checkmark$ & $\checkmark$ & $\checkmark$ & $\checkmark$ & $x$ & $\sqrt{ }$ & 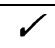 & $\checkmark$ & $\checkmark$ \\
\hline & ISR & & & & & & & & & & \\
\hline & IMR & & & & & & & & & & \\
\hline & IU & $<2$ & $\checkmark$ & $\mathscr{L}$ & $\checkmark$ & $\checkmark$ & $x$ & $\checkmark$ & 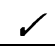 & $\mathscr{L}$ & $\mathscr{L}$ \\
\hline \multirow{4}{*}{$\begin{array}{c}\mathrm{NO}_{3}-\mathrm{N} \\
\left(\mathrm{mg} \cdot \mathrm{L}^{-1}\right)\end{array}$} & SAT & $<25$ & $\checkmark$ & $x$ & $x$ & $\checkmark$ & $\checkmark$ & $x$ & $\checkmark$ & $x$ & $x$ \\
\hline & ISR & $10-30$ & $\checkmark$ & $x$ & $\mathscr{L}$ & $\checkmark$ & $\checkmark$ & $\checkmark$ & $\mathscr{r}$ & 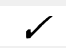 & $\checkmark$ \\
\hline & IMR & $5-10$ & $x$ & $x$ & $x$ & $x$ & & $\times$ & $x$ & $x$ & $x$ \\
\hline & $\mathrm{IU}$ & $<5$ & $x$ & $x$ & $x$ & $x$ & $x$ & $x$ & $x$ & $x$ & $x$ \\
\hline \multirow{4}{*}{$\begin{array}{c}\mathrm{TN} \\
\left(\mathrm{mg} \cdot \mathrm{L}^{-1}\right)\end{array}$} & SAT & 4- 40 & $\checkmark$ & $\checkmark$ & $\checkmark$ & $\checkmark$ & $\checkmark$ & $\checkmark$ & $\checkmark$ & $\checkmark$ & $\checkmark$ \\
\hline & ISR & $10-30$ & $x$ & $x$ & $x$ & $x$ & $x$ & $x$ & $\mathscr{J}$ & $x$ & $\checkmark$ \\
\hline & IMR & $5-10$ & $x$ & $x$ & $x$ & $x$ & $x$ & $x$ & $x$ & $x$ & $x$ \\
\hline & IU & $<5$ & $x$ & $x$ & $x$ & $x$ & $x$ & $x$ & $x$ & $x$ & $x$ \\
\hline \multirow{4}{*}{$\mathrm{pH}$} & SAT & $6.5-9.5$ & $\checkmark$ & $\checkmark$ & $\checkmark$ & $\checkmark$ & $\checkmark$ & $\checkmark$ & $\checkmark$ & $\checkmark$ & $\checkmark$ \\
\hline & ISR & $6.5-8$ & $\checkmark$ & $x$ & $x$ & $\checkmark$ & $\checkmark$ & $\checkmark$ & $\checkmark$ & $\checkmark$ & 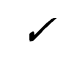 \\
\hline & IMR & $6.5-8$ & $\checkmark$ & $x$ & $x$ & $\checkmark$ & 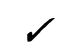 & $\checkmark$ & 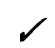 & $\Omega$ & 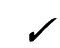 \\
\hline & IU & $6.5-8$ & $\Omega$ & $x$ & $x$ & $\checkmark$ & $\Omega$ & 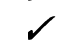 & 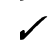 & $\Omega$ & $\Omega$ \\
\hline \multirow{4}{*}{$\begin{array}{c}\text { Total } \\
\text { coliforms } \\
\left(\text { cfu. } 100 \mathrm{~mL}^{-1}\right)\end{array}$} & SAT & $<100$ & $\checkmark$ & $\Omega$ & $\checkmark$ & $x$ & $x$ & $x$ & $x$ & $x$ & $x$ \\
\hline & ISR & $<100$ & $\checkmark$ & $\mathscr{C}$ & $\checkmark$ & $x$ & $x$ & $x$ & $x$ & $x$ & $x$ \\
\hline & IMR & $<100$ & $\checkmark$ & $\Omega$ & $\mathscr{L}$ & $x$ & $x$ & $x$ & $x$ & $x$ & $x$ \\
\hline & IU & $<10$ & $\checkmark$ & $\Omega$ & 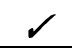 & $x$ & $x$ & $x$ & $x$ & $x$ & $x$ \\
\hline
\end{tabular}


Table 4. Carbon, capital and operational costs, and land required for the treatment technologies

\begin{tabular}{|c|c|c|c|c|c|c|}
\hline \multirow[b]{2}{*}{$\begin{array}{l}\text { Population } \\
\text { equivalents }\end{array}$} & \multicolumn{2}{|c|}{ MBR } & \multicolumn{2}{|c|}{ VF $\left(0.05\right.$ m.d $\left.^{-1}\right)$} & \multicolumn{2}{|c|}{ VF $\left(0.08 \mathrm{~m}^{-\mathrm{d}^{-1}}\right)$} \\
\hline & 5,000 & 50,000 & 5,000 & 50,000 & 5,000 & 50,000 \\
\hline $\begin{array}{l}\text { Capital cost } \\
\left(£ . \mathrm{pe}^{-1}\right)\end{array}$ & 814 & 197 & 559 & 266 & 433 & 195 \\
\hline $\begin{array}{l}\text { Land footprint } \\
\left(\mathrm{m}^{2} \cdot \mathrm{pe}^{-1}\right)\end{array}$ & 0.05 & 0.03 & 11.9 & 11.9 & 7.4 & 7.4 \\
\hline $\begin{array}{l}\text { Operational cost } \\
\left(£ \cdot \mathrm{pe}^{-1} \cdot \mathrm{year}^{-1}\right)\end{array}$ & 30 & 15 & 22 & 22 & 14 & 14 \\
\hline $\begin{array}{l}\text { Present Worth } \\
\text { (£; } i=5 \%, 20 \text { years) }\end{array}$ & $-5.9 \mathrm{M}^{*}$ & $-19.3 \mathrm{M}^{*}$ & $-4.1 \mathrm{M}^{*}$ & $-26.9 M^{*}$ & $-3.1 \mathrm{M}^{*}$ & $-18.3 \mathrm{M}^{*}$ \\
\hline $\begin{array}{l}\text { Carbon footprint } \\
\left(\mathrm{kg} \mathrm{CO}_{2 \mathrm{eq}} \cdot \mathrm{pe}^{-1} \cdot \mathrm{year}^{-1}\right)\end{array}$ & 57 & 50 & 8 & 8 & 5 & 5 \\
\hline
\end{tabular}




\section{Figure Captions}

Figure 1. Experimental set up and sampling points in circles; (a) CAS, (b) VF, (c) CAS+VF, and (d) MBR.

Figure 2. Box and whiskers plots for (a) COD, (b) ammonia, (c) total phosphorus, (d) nitrate, (e) total coliforms, (f) TSS. Boxes represent the $25^{\text {th }}$ and $75^{\text {th }}$ quartiles and whiskers show the maximum and minimum values.

Figure 3. (a) Weekly average infiltration rate normalised to $20^{\circ} \mathrm{C}$, (b) infiltration rate changes against cumulative solids load.

Figure 4. Impact of hydraulic loading rate on the whole life cost of the VF upgrade option in comparison to an MBR. 


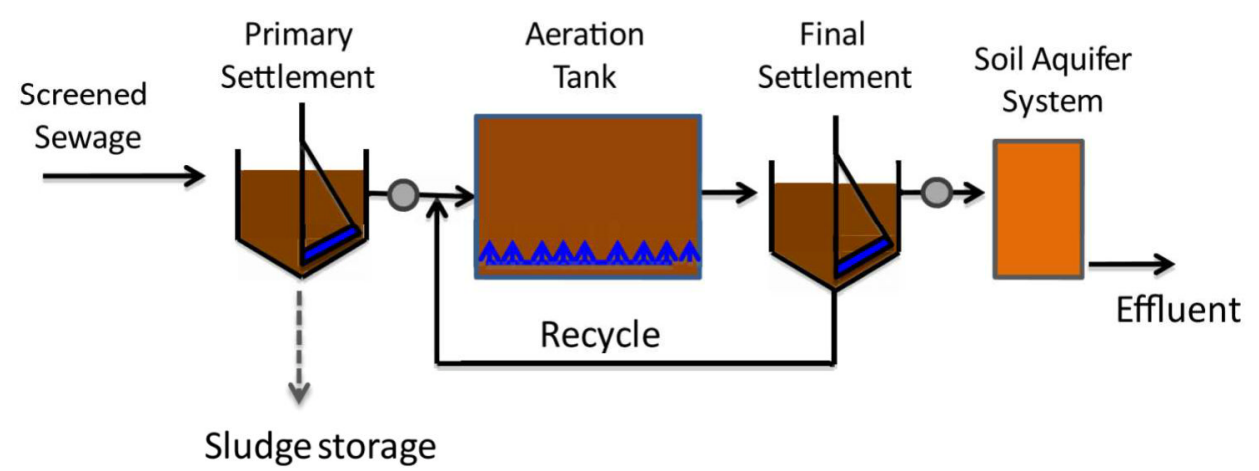

Figure $1 \mathrm{~A}$

$435 \times 172 \mathrm{~mm}(300 \times 300$ DPI $)$ 


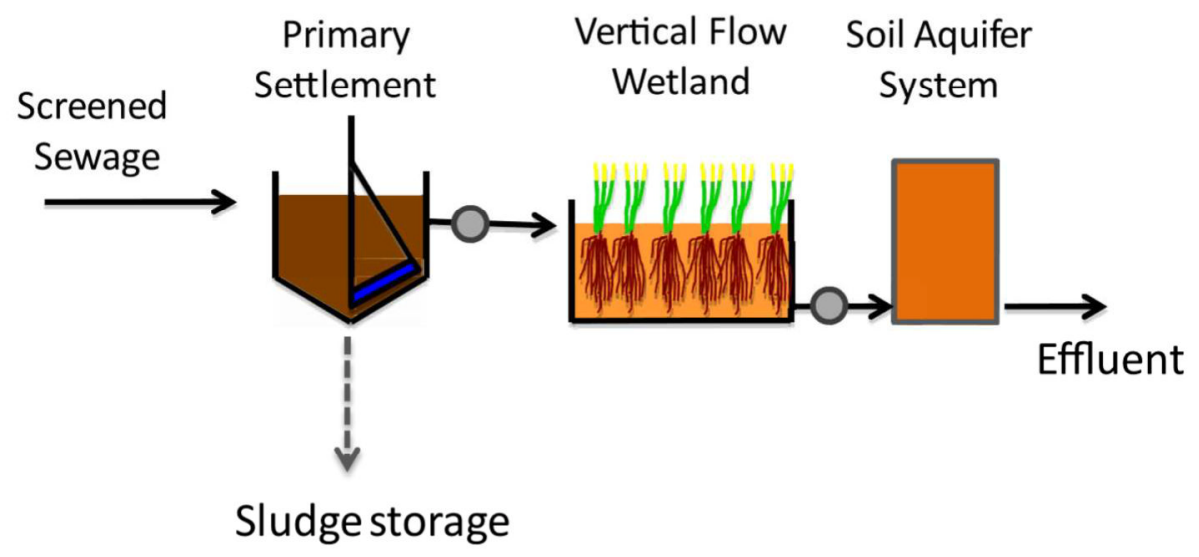

Figure 1B

$367 \times 171 \mathrm{~mm}(300 \times 300$ DPI) 


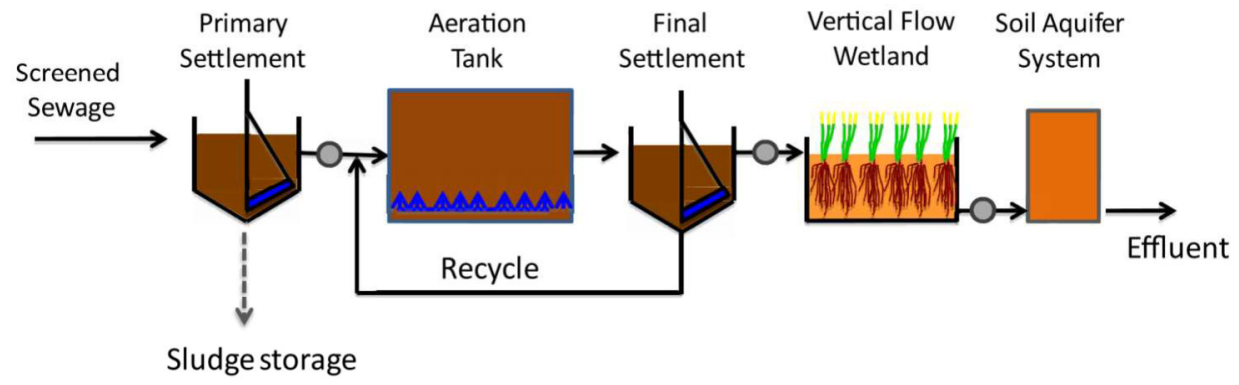

Figure $1 \mathrm{C}$

$425 \times 145 \mathrm{~mm}(300 \times 300 \mathrm{DPI})$ 


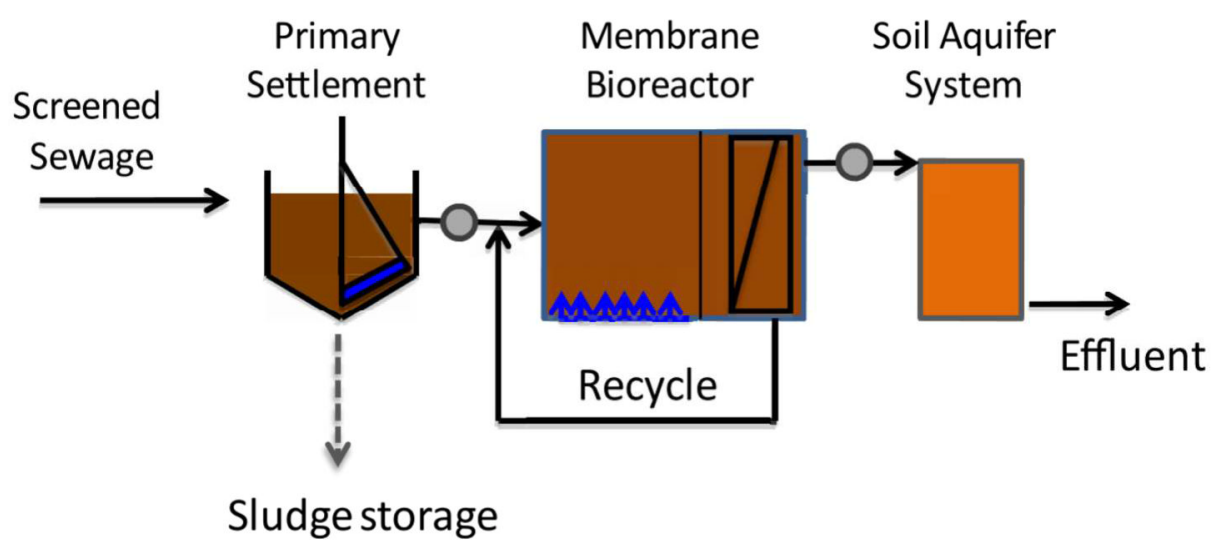

Figure 1D

$374 \times 177 \mathrm{~mm}(300 \times 300 \mathrm{DPI})$ 


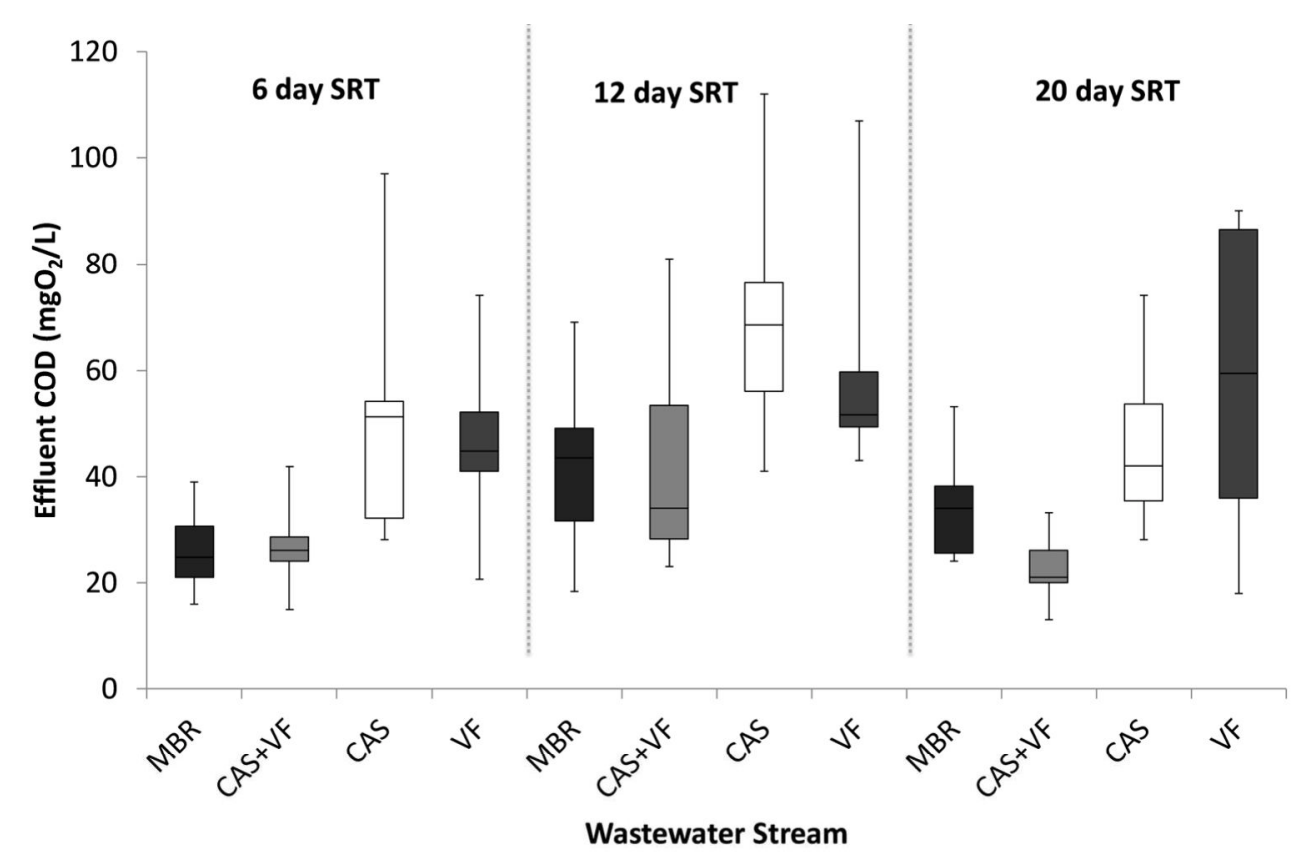

Figure 2A

$168 \times 109 \mathrm{~mm}(300 \times 300 \mathrm{DPI})$ 


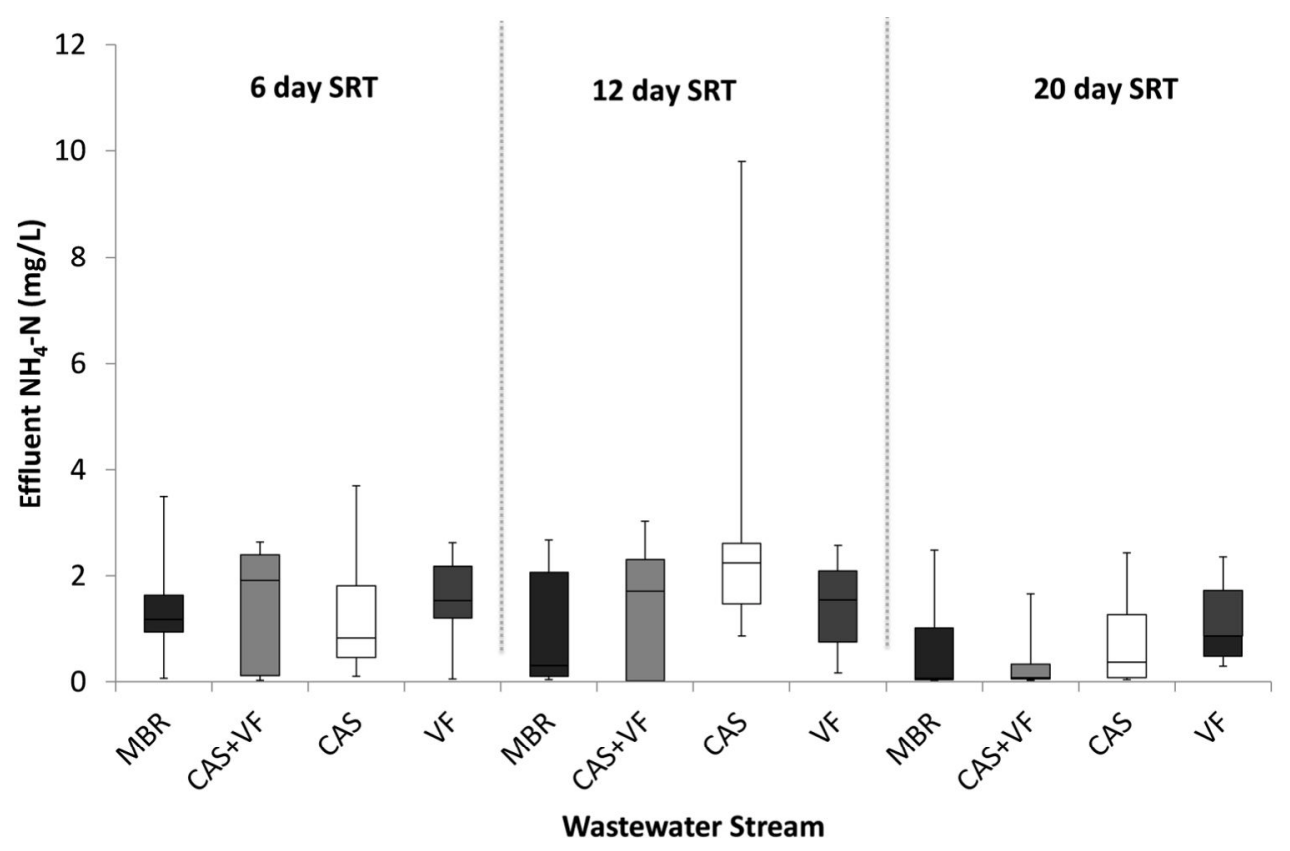

Figure 2B

$168 \times 109 \mathrm{~mm}(300 \times 300 \mathrm{DPI})$ 


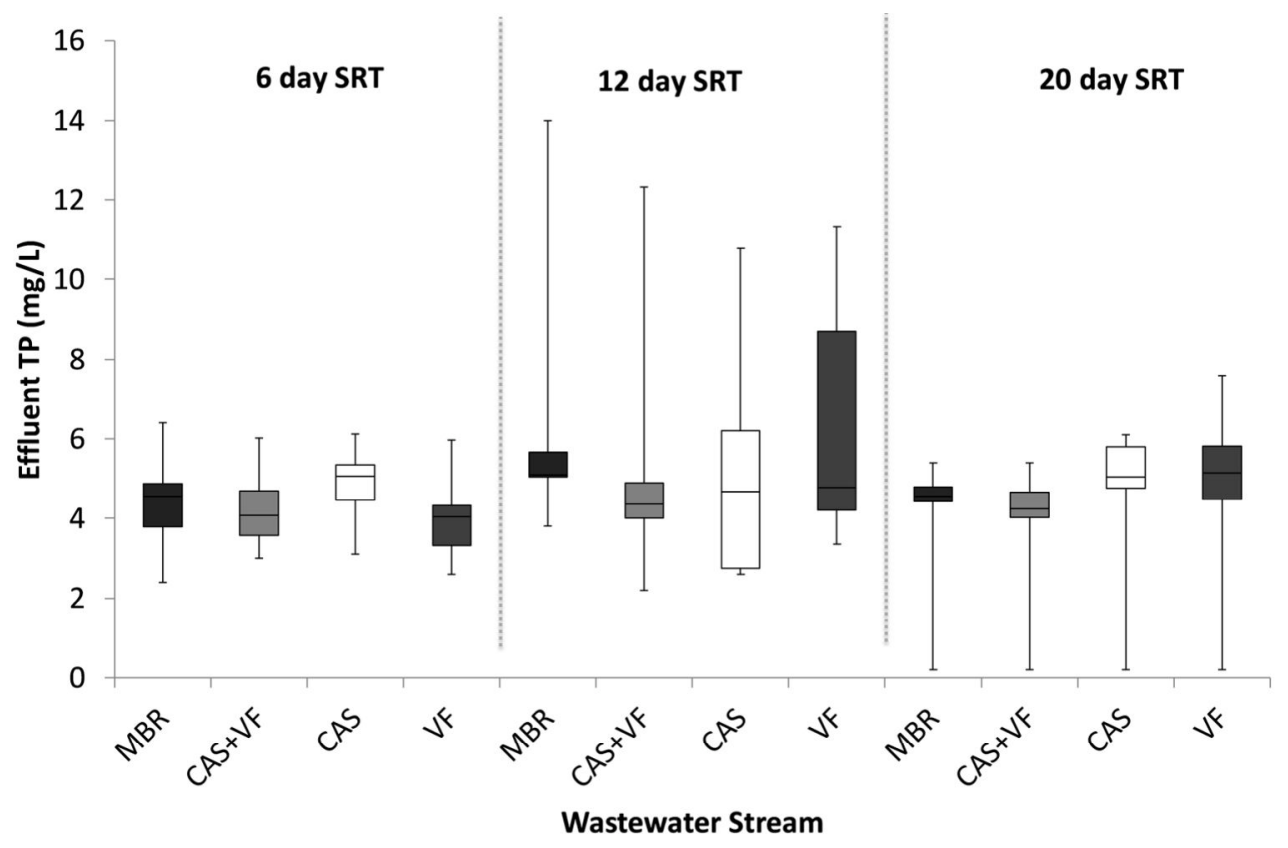

Figure 2C

$168 \times 109 \mathrm{~mm}(300 \times 300 \mathrm{DPI})$ 


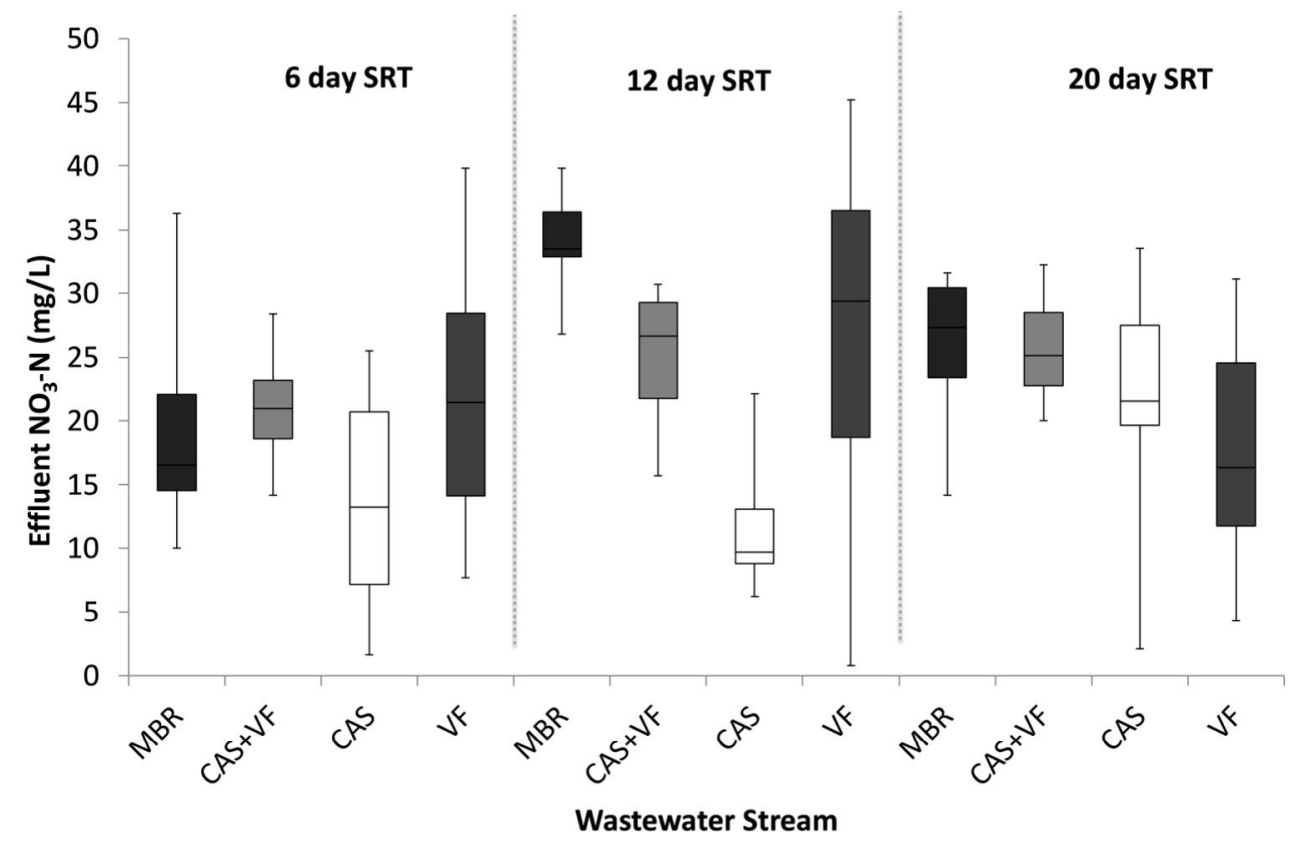

Figure 2D

$168 \times 109 \mathrm{~mm}(300 \times 300$ DPI $)$ 


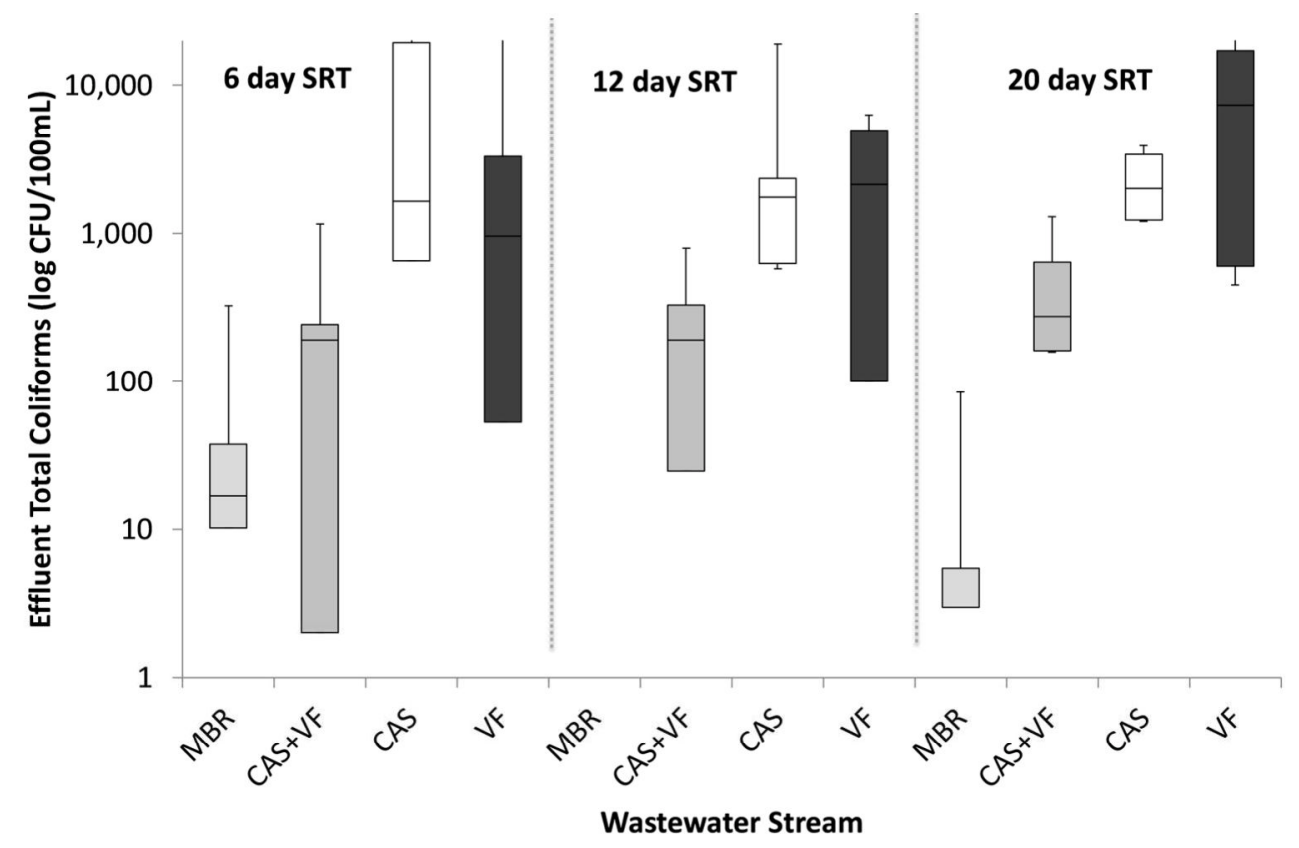

Figure 2E

$168 \times 109 \mathrm{~mm}(300 \times 300$ DPI $)$ 


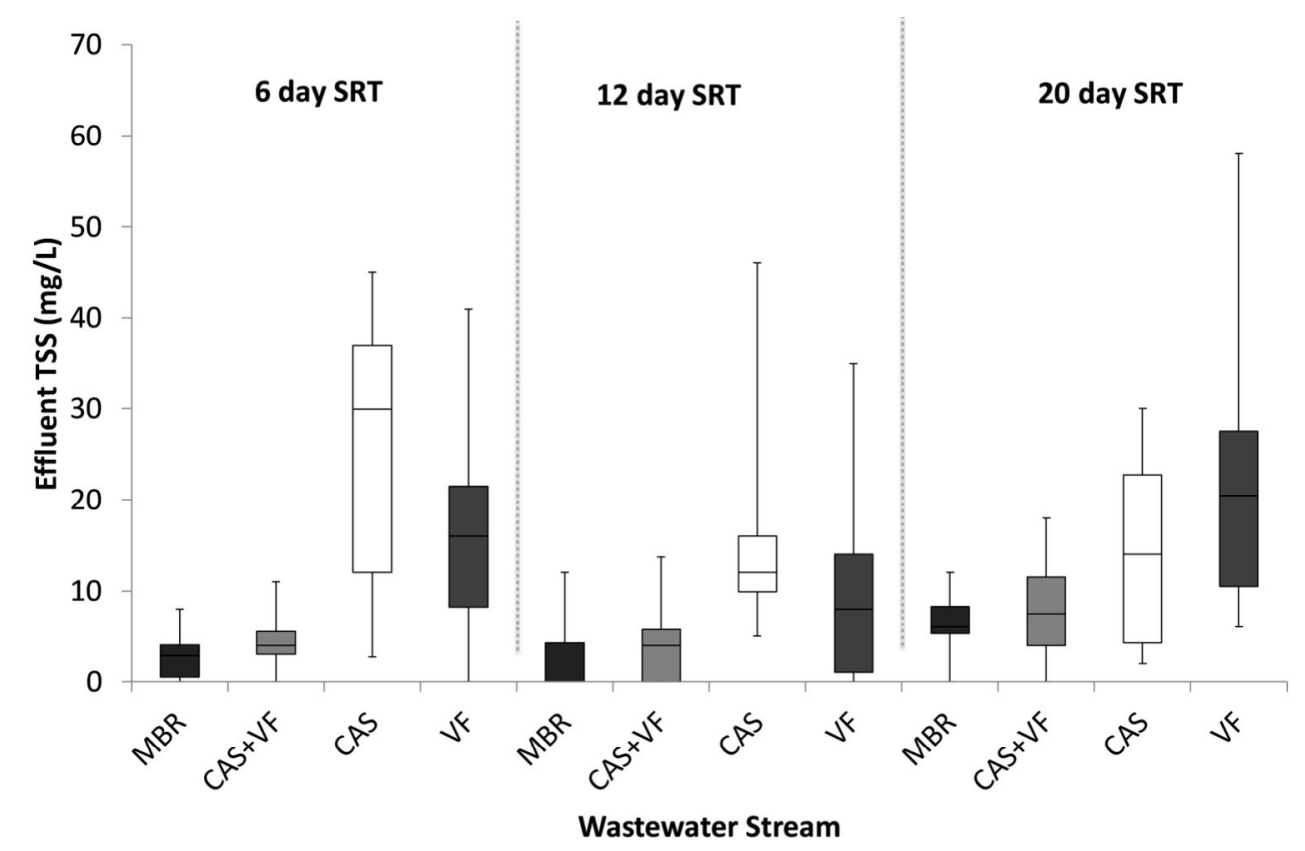

Figure $2 \mathrm{~F}$

$168 \times 109 \mathrm{~mm}(300 \times 300 \mathrm{DPI})$ 


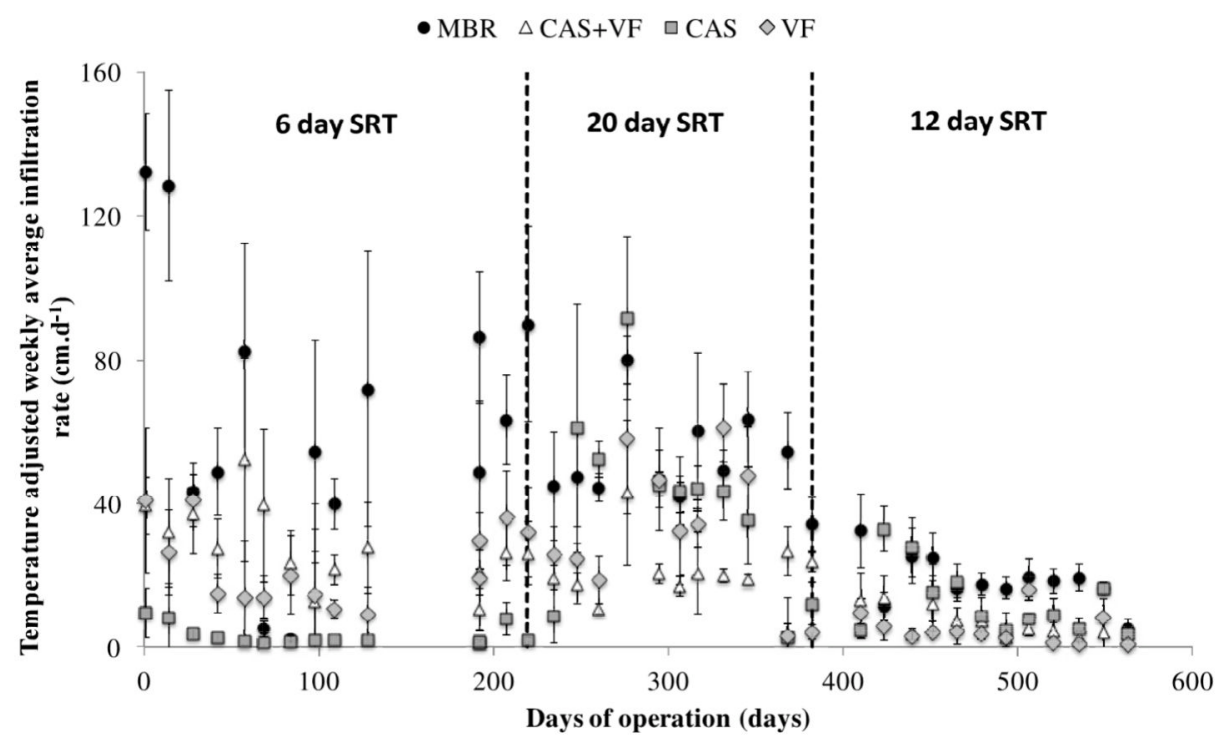

Figure 3A

$399 \times 227 \mathrm{~mm}(300 \times 300 \mathrm{DPI})$ 


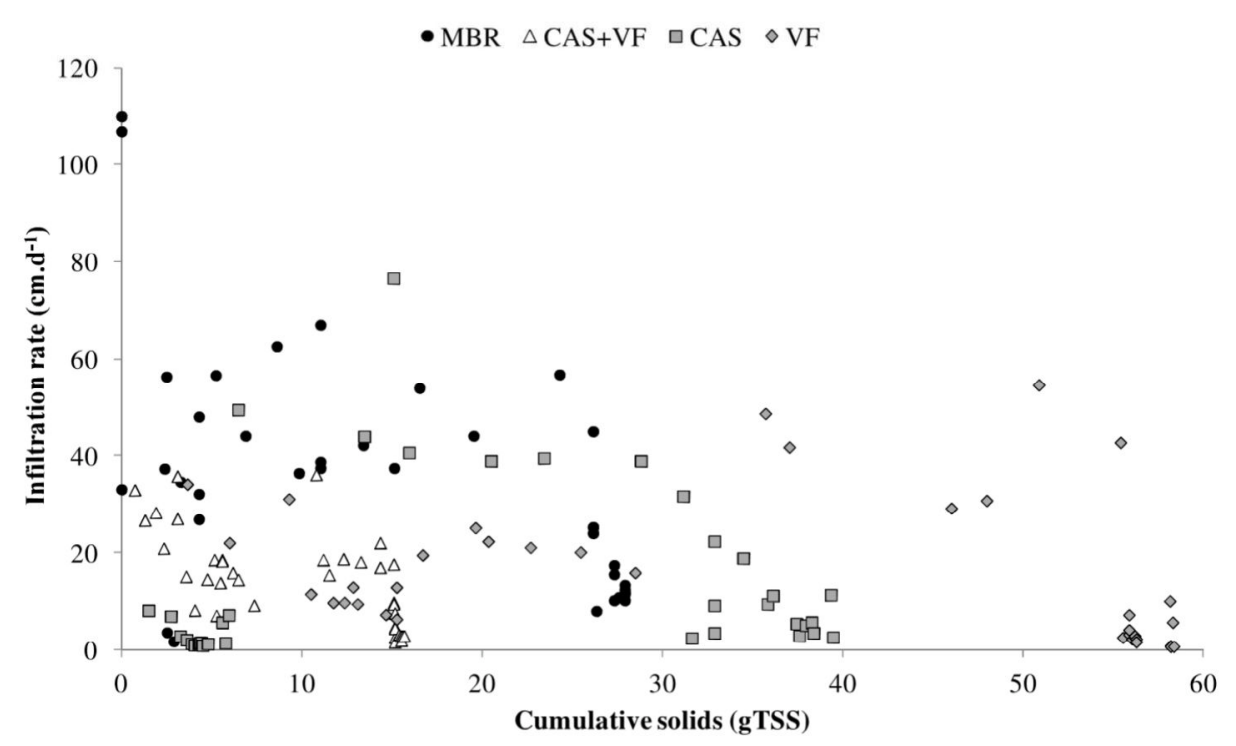

Figure 3B

$398 \times 237 \mathrm{~mm}(300 \times 300$ DPI) 


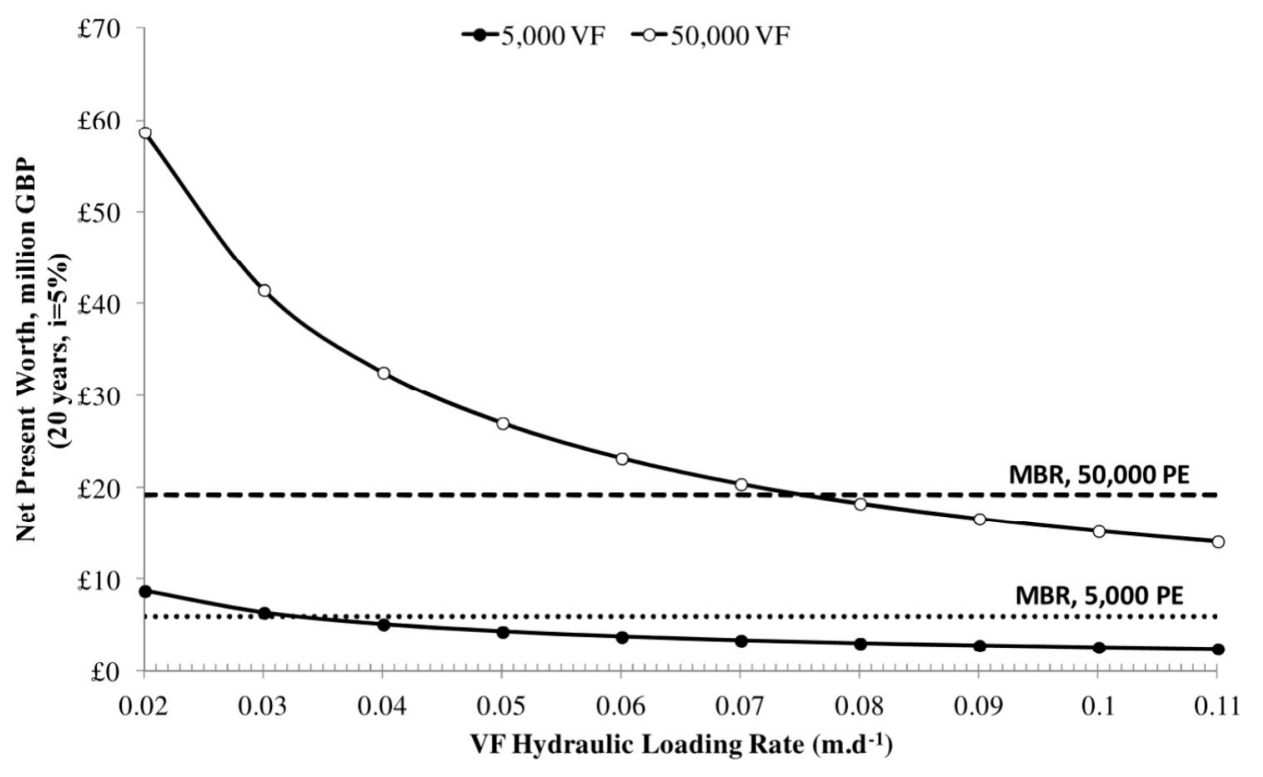

Figure 4

$385 \times 231 \mathrm{~mm}(300 \times 300 \mathrm{DPI})$ 